\title{
高速液体クロマトグラフィーによるショ糖脂肪酸エステルの定量
}

(平成元年 2 月 23 日受理)

村上千秋* 丸山武紀* 新 谷 勛*

\section{Determination of Sucrose Esters of Fatty Acids by High Performance Liquid Chromatography}

\author{
Chiaki Murakami, Takenori Maruyama and Isao Nirya \\ (Japan Institute of Oils \& Fats, Other Foods Inspection, Foundation: \\ 3-27-8, Nihonbashi-Hamacho, Chuo-ku, Tokyo, Japan)
}

\begin{abstract}
A sensitive method was developed for the quantitative determination of sucrose monoand di-fatty acid esters (SuE) in foods by high performance liquid chromatography (HPLC). The SuE were extracted with tetrahydrofuran from foods and purified by silica gel column chromatography. The isolated SuE were derivatized with 3, 5-dinitrobenzoyl chloride (DNBC) and the reaction products were dissolved in a mixture of tetrahydrofuran and acetonitrile (1: 1). A portion of this solution was injected into an Inertsil $\mathrm{C} 8$ column and eluted with a linear gradient elution system from $15 \%$ water in acetonitrile to $100 \%$ acetonitrile over $30 \mathrm{~min}$, then hold for $20 \mathrm{~min}$.

Each SuE was detected with a UV detector set at $230 \mathrm{~nm}$. SuE in various kinds of foods could be selectively detected without interference on the HPLC. All peaks of mono- and diesters having $\mathrm{C}_{12}, \mathrm{C}_{14}, \mathrm{C}_{16}, \mathrm{C}_{18} \mathrm{C}_{16}-\mathrm{C}_{16}, \mathrm{C}_{16}-\mathrm{C}_{18}$ and $\mathrm{C}_{18}-\mathrm{C}_{18}$ carbon chains could be well separated. The recoveries of SuE added to margarine, ice cream, cookies, curry roux and coffee whitener were more than $80 \%$ for the monoesters and more than $75 \%$ for the diesters. The detection limit was $0.001 \%$ for each SuE.
\end{abstract}

(Received February 23, 1989)

Key words: 高速液体クロマトグラフィー high performance liquid chromatography; 乳化剤 emulsifier; ショ糖脂肪酸エステル sucrose esters of fatty acids; マーガリン margarine; アイス クリーム ice cream; クッキー cookie

緒言

ショ糖脂肪酸エステル $(\mathrm{SuE})$ は, 結合する脂肪酸の種 類及びエステル化度を変えることにより幅広い性質のも のを作ることができる．加工食品では乳化剤のみならず 小麦粉二次製品の保存性向上や食感改良, 油脂の結晶成 長の制御，インスタントカレー, キャンデー，チュウイ ンガム, 魚肉練り製品の保存性向上の目的に, さらに, 打錠菓子の滑沢剂としても用いられている

食品中の SuE の分析は, 現在カラムクロマトグラフ ィー, ガスクロマトグラフィー $(\mathrm{GLC})^{2), 4)}$ や薄層クロマ トグラフィー (TLC), 比色分析法5なよ゙で行われている. GLC による定量の場合, 分析可能な SuE は, モノェス テル及び短鎖脂肪酸のジェステルに限られて2, さらに不

* (財) 日本食品油脂検査協会: 東京都中央区日本橋浜町 327-8
純物との分離が困難である．TLCによる場合は操作が 煩雑で分析に長時間を要し，また定量精度が低いなどの 欠点がある。

近年，高速液体クロマトグラフィー (HPLC) による分 析が報告6されたが，SuEの品質管理への試みであり， 実際の食品への応用例は見当たらない。

著者らは，先に油脂食品中のモノグリセリドの定量に UV ラベル化剂を用い，HPLC で測定する方法を報告7) した。この方法を我が国で用いられているショ糖脂肪酸 エステルの大部分を占める゙立ノ及びジェステルの定量 に応用し，良好な結果を得たので報告する。

\section{実験方法}

1. 試料

抽出溶媒及び添加回収率検討用のマーガリン, アイス クリーム， カレールーは，SuE 無添加の市販品を用い 
Sample $(5 \mathrm{~g})$

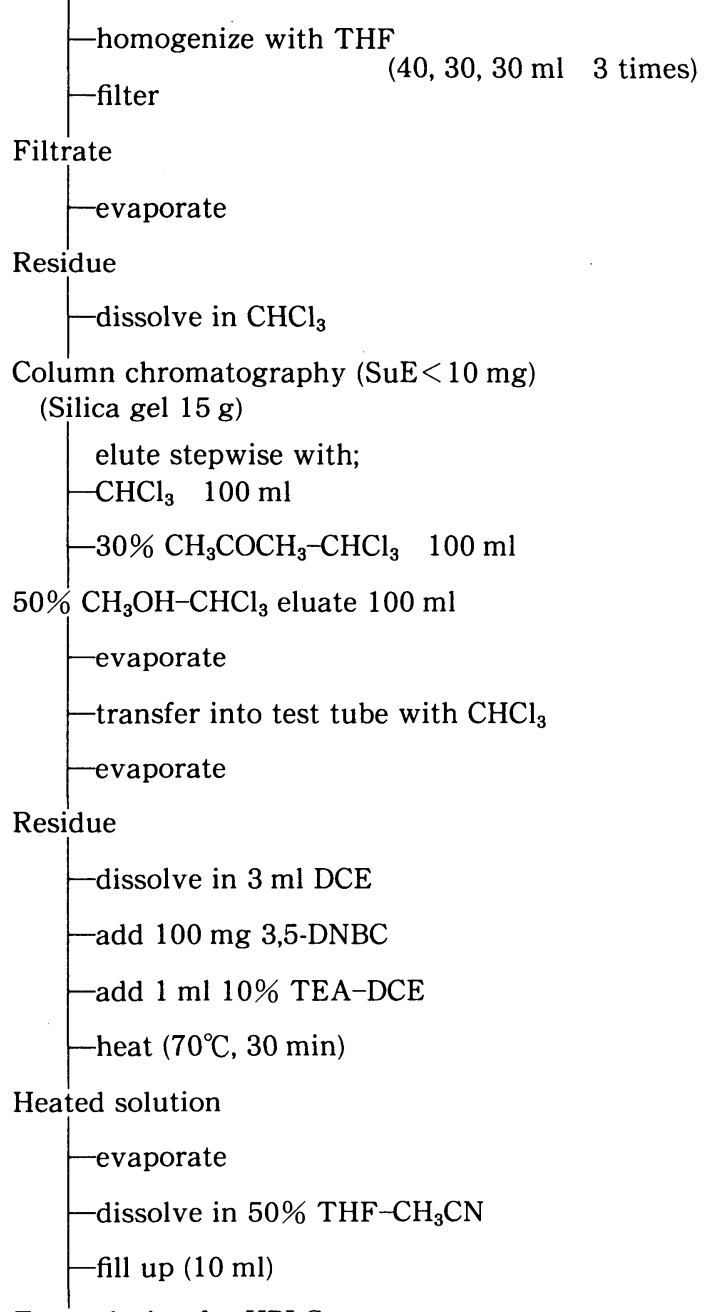

Test solution for HPLC

HPLC condition column: Inertsil $\mathrm{C} 8(4.6 \mathrm{~mm}$ i.d. $\times 250 \mathrm{~mm})$ mobile phase: (A) $15 \% \mathrm{H}_{2} \mathrm{O}-\mathrm{CH}_{3} \mathrm{CN} \rightarrow$ (B) $100 \%$ $\mathrm{CH}_{3} \mathrm{CN}$, gradient for $30 \mathrm{~min}$, following to (B) for $20 \mathrm{~min}$.

flow rate: $1.0 \mathrm{ml} / \mathrm{min}$ detector: UV wavelength $230 \mathrm{~nm}$ injection volume: $20 \mu \mathrm{l}$ DCE: dichloroethane

DNBC: dinitrobenzoyl chloride

TEA: triethylamine THF: tetrahydrofuran

Scheme 1. Analytical procedure for determination of sucrose mono- and di-fatty acid esters in foods
た. 添加回収実験用のクッキーは，モノ，ジェステルの 混合物を無水物換算で $0.1 \%$ 添加して焼成したものを用 いた. ただし，焼成を， $170^{\circ}$ で行うと SuE が一部分解す るので, 減圧下 $85^{\circ}$ で焼成した。 市販品への応用にはマ ーガリン, アイスクリーム, カレールー, コーヒーホワ イトナー, タブレット（カルシウム, 食物繊維を強化し た打錠菓子)，ホイップクリーム，クッキーを用いた。

\section{2. 試薬}

$\mathrm{SuE}$ 同定用標準品：ショ糖ラウリン酸モノエステル, ショ糖ミリスチン酸モノエステル, ショ糖パルミチン酸 モノエステル, ショ糖ステアリン酸モノエステルは, 第 一工業製薬(株)より恵与されたもので，HPLCにおける モノエステルの同定に用いた。

SuE 定量用標準品: 市販の SuE (第一工業製薬(株)製 の DK エステル F-50）を用い 6.SuE 定量用標準品の調 製の項に従ってモノ及びジェステルを調製した。

3, 5- ジニトロ塩化ベンゾイル (DNBC): HPLC 用 UV ラベル化剂, 半井化学(株)製

シリカゲル：カラムクロマトグラフィー用, 100〜200 mesh 和光純薬工業(株)製

その他の試薬は, すべて市販特級品を用いた。

\section{3. 装置及び器具}

ロータリーエバポレーター：柴田科学機械工業(株)製 RE 120-B型

ホモジナイザー：JANKE \& KUNKEL GMB 社製 Ultraturrax

高速液体クロマトグラフ：(株)日立製作所製 LC 655 A-11 型

検出器：(株)島津製作所製 SPD-6AV 型 データープロセッサー：(株) 日立製作所製 655-71 型 HPLC インジェクター：RHEODYNE 社製 7125 型 シリカゲルカラム：分析用カラムは，5\%含水させた シリカゲル $15 \mathrm{~g}$ を内径 $1.5 \times 30 \mathrm{~cm}$ のガラス管にクロ ロホルムで湿式法により充てんした，また，標準品調製 用力ラムは, $105^{\circ}$ で 16 時間活性化したシリカゲル $10 \mathrm{~g}$ を内径 $1.0 \times 30 \mathrm{~cm}$ のガラス管にクロロホルムにより充 てんした.

\section{HPLC 操作条件}

カラム: Inertsil C8, $4.6 \mathrm{~mm}$ i.d. $\times 250 \mathrm{~mm}$ (ガスクロ 工業(株)製)

移動相：15\% 含水アセトニトリル（A 液）から 100\% アセトニトリル（B 液）に 30 分で変化するように濃度 勾配法で行い, B 液に達した後 20 分間保持した。

流量: $1.0 \mathrm{ml} / \mathrm{min}$

測定波長： $230 \mathrm{~nm}$

注入量: $20 \mu 1$

\section{5. 試験溶液の調製}

\section{1 抽出操作}

液体試料の場合はそのまま, 固体試料の場合は細切 


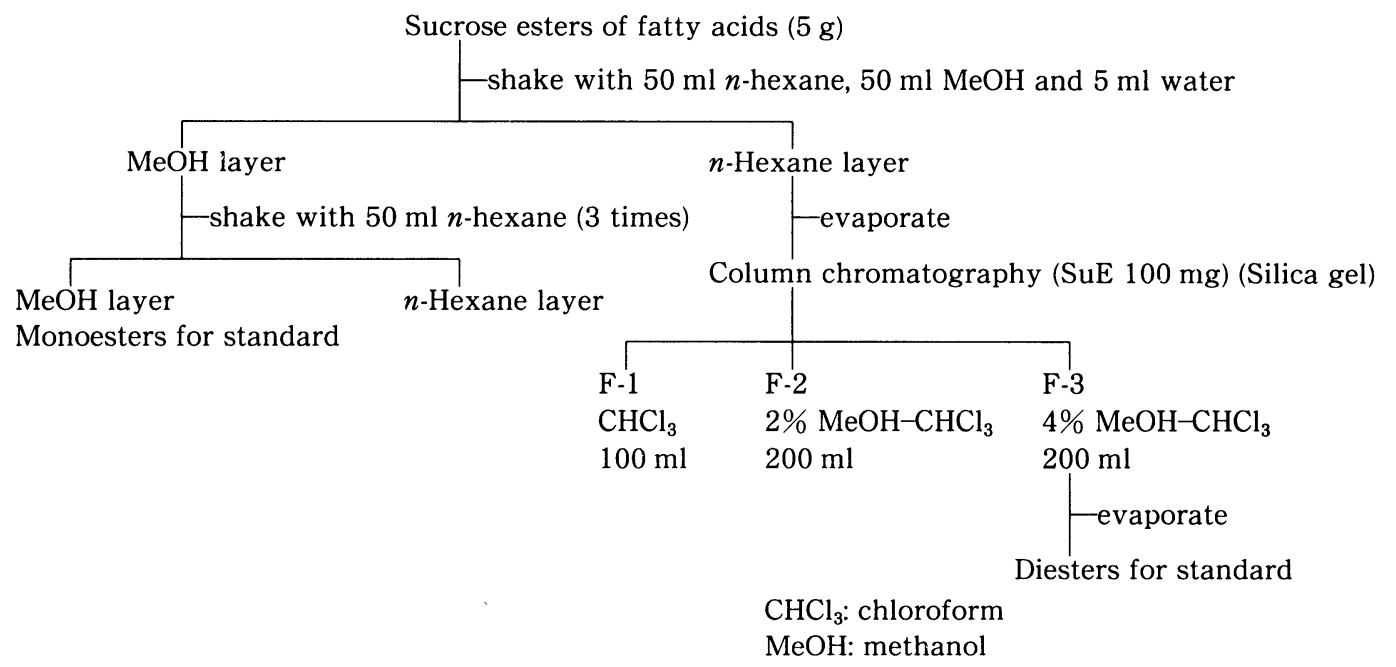

Scheme 2. Preparation of sucrose mono- and di-fatty acid esters for standard

し,その $5 \mathrm{~g}$ を $50 \mathrm{ml}$ 容の遠沈管にはかり取り, テトラ ヒドロフランを約 $40 \mathrm{ml}$ 加えて 3 分間ホモジナイズし, 上澄液をろ過または遠心分離する. 残留物にテトラヒド ロフランを約 $30 \mathrm{ml}$ 加え, 同様の操作を 2 回繰り返しこ れらの上澄液を合わせ減圧下で蒸発乾固する. 残留物を クロロホルムに溶解して正確に $10 \mathrm{ml}$ とし, SuE 抽出 溶液とした。

\section{2 シリカゲルカラムによる精製}

$\mathrm{SuE}$ 抽出溶液の一部（総 $\mathrm{SuE}$ として $10 \mathrm{mg}$ 以下にな るように, 通常 $2 \mathrm{ml}$ ) をシリカゲルカラムに負荷し, ク ロロホルム $100 \mathrm{ml}$, 次いでアセトンークロロホルム混液 (30:70) $100 \mathrm{ml}$ で展開した後, メタノールークロロホル ム混液 $(50: 50) 100 \mathrm{ml}$ で SuE を溶出する. この溶出液 を減圧濃縮し, クロロホルムで $20 \mathrm{ml}$ の共栓付き試験管 に移し減圧下で蒸発乾固して, SuE 画分とする.

\section{$5.3 \mathrm{DNBC}$ 誘導体の調製}

$\mathrm{SuE}$ 画分をジクロロエタン $3 \mathrm{ml}$ に溶解し, 3,5DNBC $100 \mathrm{mg}$ と 10\% トリエチルアミンージクロロエ

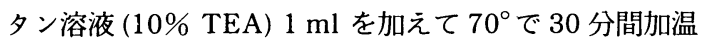
し, エステル化を行う. 反応終了後, 滅圧下で蒸発乾固 し，これにテトラヒドロフランーアセトニトリル混液 (1: 1) を正確に $10 \mathrm{ml}$ 加えて溶解し, HPLC 用検液とする. 検液 $20 \mu \mathrm{l}$ を HPLCに注入して SuE のピーク面積を求 め, あらかじめ作成しておいた検量線から定量する.こ の操作の概略を Scheme 1 に示した.

\section{SuE 定量用標準品の調製}

$\mathrm{SuE}$ のモノェステル及びジェステルの標準品は市販 されていないため, 食品添加物規格品の SuE からこれ らを液液分配息及びシリカゲルカラムで分離精製91 ${ }^{10)} し$ た.

モノ， ジェステル定量用標準品の調製は, DK エステ
ル F-50 $5 \mathrm{~g}$ を分液漏斗に取り, $n$-ヘキサン $50 \mathrm{ml}$, メ夕 ノール $50 \mathrm{ml}$, 水 $5 \mathrm{ml}$ の混液で液液分配 ${ }^{8}$ を行い, 下層 の含水メタノール層を $n$-ヘキサンで洗浄した後, 隇圧下 で蒸発乾固しモノエステル画分を得た. 次いで, TLCで モノエステルのみであることを確認した後標準品とし た. 上層の $n$-ヘキサン層は減圧下で蒸発乾固して, その $100 \mathrm{mg}$ をシリカゲルカラムに負荷し, クロロホルム $100 \mathrm{ml}, 2 \%$ メタノールークロロホルム $200 \mathrm{ml}$ で展開 し, 大部分のポリ, トリエステルを除いた後 $4 \%$ ×夕 ールークロロホルム $200 \mathrm{ml}$ を $50 \mathrm{ml}$ ずつに 4 分画しジ エステルを得た ${ }^{91.10)}$. ジェステルの各画分を減圧蒸発乾 固し，TLCでジェステルのみであることを確認した後, これらを定量用標準品として用いた。なお，TLCは，ク ロロホルムーメタノールー酶酸一水 $(40: 5: 4: 1)$ で展開 後, アンスロン試液を噴霧し加熱後, 青色のスポットの $R f$ 值により確認した ${ }^{5)}$ ．モノ及びジェステル調製操作の 概略を Scheme 2 に示した。

\section{7. 検量線の作成}

モノ及びジェステルの $2 \mathrm{mg} / \mathrm{ml}$ テトラヒドロフラン 溶液を調製し，これらを合わせ標準溶液とする。この溶 液の $1.0 \sim 4.0 \mathrm{ml}$ をそれぞれ採取した. 以後, 5. 試験溶 液の調製の $5.3 \mathrm{DNBC}$ 誘導体の調製に従って DNBC 誘 導体とし，HPLC に注入する. 得られたクロマトグラム からモノ及びジェステルに相当するそれぞれのピーク面 積を求め, その総和と注入量 $(\mu \mathrm{g})$ とから検量線を作成す る.

\section{結果及び考察}

\section{1. 誘導体の調製}

モノグリセリドの定量にUVラベル化剤として DNBC を用い，TEA 存在下でェステル化する方法を先 に報告7)した．そこで SuE の定量にもこの方法を応用す 


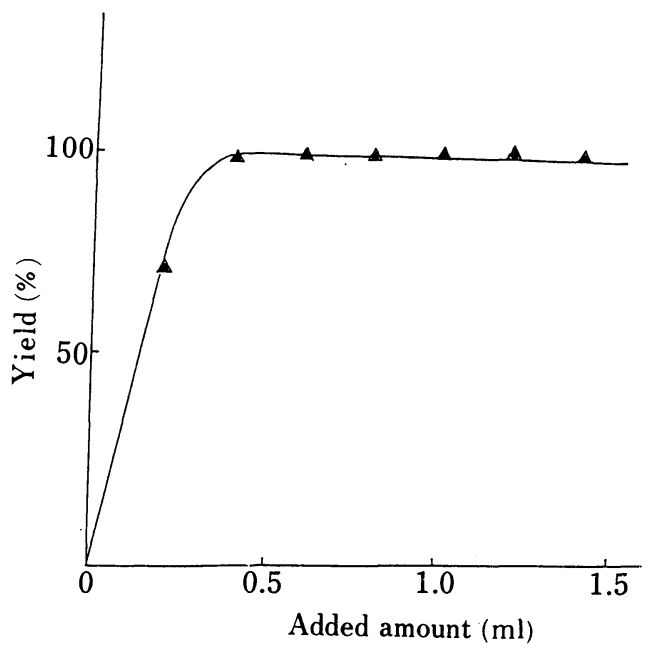

Fig. 1. Effect of added amount of $10 \%$ triethylamine solution on yield of DNBC derivatives of sucrose mono- and di-fatty acid esters

Mixture of the mono- and diesters (10 $\mathrm{mg}$ ) were reacted with $100 \mathrm{mg}$ of 3,5 $\mathrm{DNBC}$, at $70^{\circ} \mathrm{C}$ for $15 \mathrm{~min}$.

$\triangle-$ monoesters; $\triangle \longrightarrow$ : diesters

ることとした，しかし，SuEはエステル化度がさまざま であり，また，水酸基の数も多いため，モノグリセリド での反応条件をそのまま適用することはできない，そこ で誘導体の調製方法について検討した，反応は DNBC の量を $100 \mathrm{mg}$ とし, SuEと TEA 量を変化させて行っ た. 反応率は反応前後の $\mathrm{SuE}$ を赤外吸収スペクトルで 測定し，その-OH の吸収率から求めた。 DNBC を 100 $\mathrm{mg}$, モノ，ジェステルをそれぞれ $10 \mathrm{mg}$ と一定にして 10\% TEA 量を変化させた結果を Fig. 1 に示した. モ ノ, ジェステルとも 10\% TEA が約 $0.5 \mathrm{ml}$ 以上になる と反応率はほぼ 100\% になったので， $1 \mathrm{ml}$ 加えること とした.

次に, DNBC の量を $100 \mathrm{mg}, 10 \%$ TEA の量を $1 \mathrm{ml}$ とし, モノ, ジェステルの量を変化させて得られた結果 をFig. 2 に示した. モノェステルでは $10 \mathrm{mg}$, ジェステ ルでは $12 \mathrm{mg}$ までほぼ $100 \%$ の反応率であった. SuE はモノグリセリドに比べて水酸基の数が多いため DNBC 及び TEA 量が 2.5 倍必要であった。

\section{HPLC}

SuE-DNBC 誘導体の分離はカラムに Inertsil ODS を 用いた場合, 移動相のアセトニトリルー水の混合比をい ろいろ変化させてもモノエステルの溶出に時間がかか り,さらにジェステルはピークとして出現しなかった. しかし, Inertsil C8 カラムでは移動相に含水アセトニト リルを用いると, モノェステル及びジェステルとも溶出

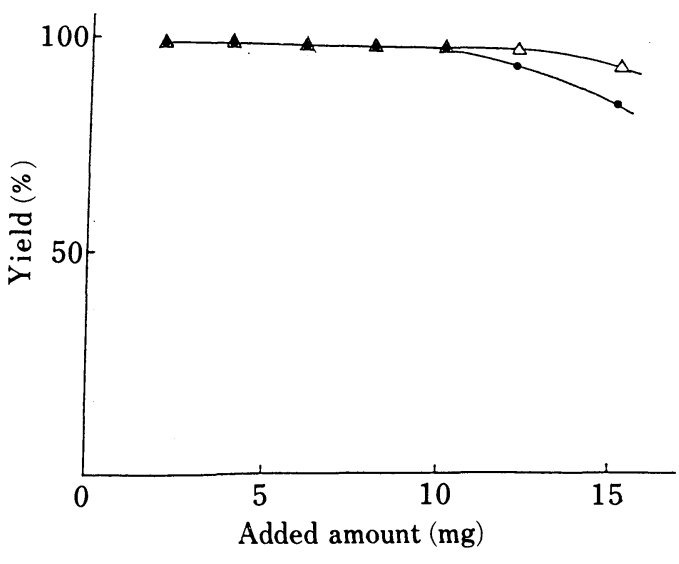

Fig. 2. Effect of added amount of sucrose mono- and di-fatty acid esters on yield of DNBC derivatives

The mono- and diesters were reacted with $100 \mathrm{mg}$ of 3,5-DNBC and $1 \mathrm{ml}$ of $10 \%$ TEA solution at $70^{\circ} \mathrm{C}$ for $15 \mathrm{~min}$.

$\triangle$ : monoesters; $\triangle \longrightarrow \triangle$ : diesters

した. そこで，これらの適切な分離条件を検索した。 セトニトリル中の含水量を $15 \%$ にし，濃度勾配法によ り 30 分間で 100\%アセトニトリルに変え, その状態で 20 分間保持すると各 SuE が相互に分離された (Fig. 3). アシル基が $\mathrm{C}_{12} \sim \mathrm{C}_{18}$ までのモノェステル及び, $\mathrm{C}_{16}$ 上 $\mathrm{C}_{18}$ から成るジェステルの溶出時間は約 50 分であった.

モノエステルからは，いずれも 2 本のピークが検出さ れた。これはショ糖の 6 位，または，6' 位に脂肪酸が結 合した位置異性体と考える。 また，アシル基が $\mathrm{C}_{16}$ と $\mathrm{C}_{18}$ から構成されるジェステルでは，主ピークが 3 本に 分離した。これはショ糖の 6 位と $6^{\prime}$ 位に脂肪酸が結合 した $\left(\mathrm{C}_{16}-\mathrm{C}_{16}\right),\left(\mathrm{C}_{16}-\mathrm{C}_{18}\right),\left(\mathrm{C}_{18}-\mathrm{C}_{18}\right)$ の位置異性体にそれぞ れ相当するものと推定した。

\section{3. 抽出溶媒}

各種食品から $\mathrm{SuE}$ を抽出する溶媒について検討した. 抽出溶媒にはテトラヒドロフラン, イソブタノール, メ タノール, クロロホルム, クロロホルムーメタノール (1: 1)及びジクロロエタンを用いて抽出率を比較した (Table 1). テトラヒドロフランは, モノ，ジェステルの 抽出率が，他の溶媒に比べて良好であり，さらに濃縮し やすいことから抽出溶媒 ${ }^{4)}$ に用いた。

\section{4. 妨害物質の除去}

DNBC と反応し HPLC 上で妨害が予想される化合物 は, 乳化剂ではグリセリンモノ, シ脂肪酸エステル, プ ロピレングリコール脂肪酸エステル, ソルビタン脂肪酸 エステル，その他には油脂由来のトコフェロール，ステ ロール類などが想定される.この除去操作にシリカゲル カラムを用いた．まず最初にクロロホルム $100 \mathrm{ml}$ で展 


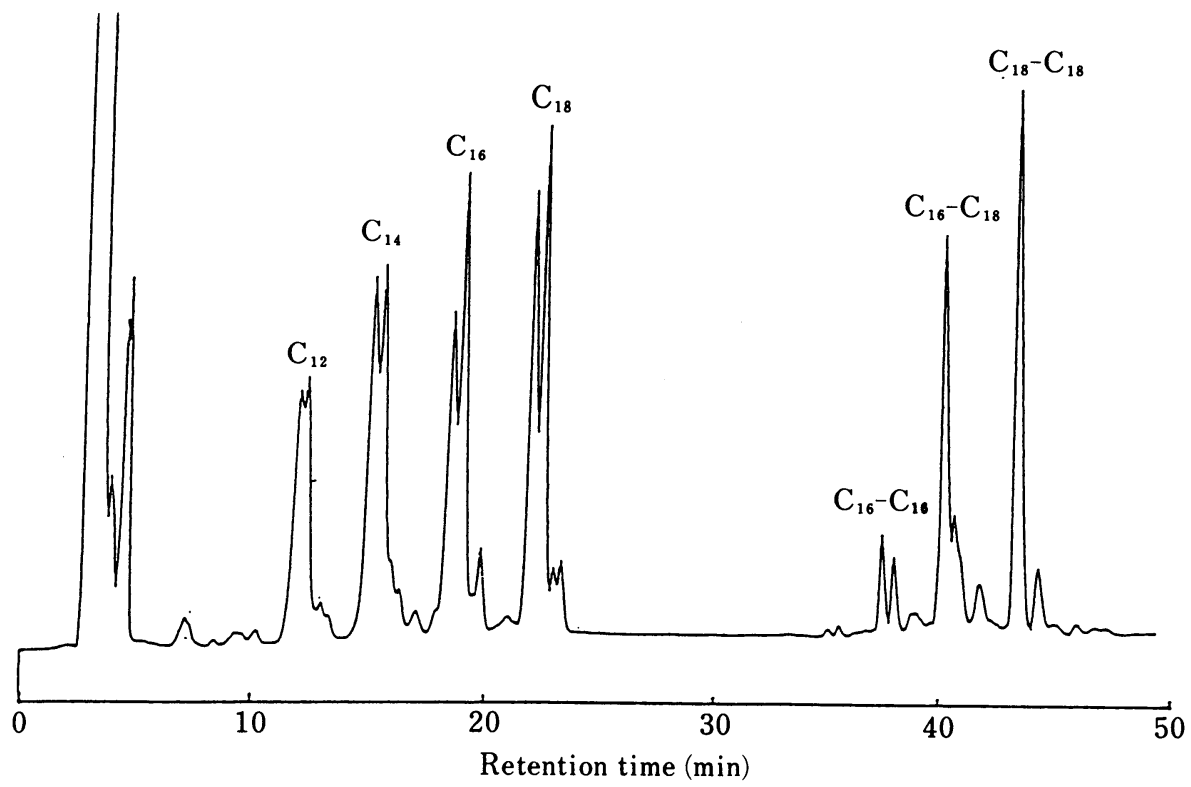

Fig. 3. Elution patterns of DNBC-derivatives of sucrose mono- and di-fatty acid esters by high performance liquid chromatography

HPLC condition: column, Inertsil C8 (4.6 mm i.d. $\times 250 \mathrm{~mm}$ ); mobile phase, $15 \% \mathrm{H}_{2} \mathrm{O}$ in $\mathrm{CH}_{3} \mathrm{CN}(\mathrm{A})$ and $100 \% \mathrm{CH}_{3} \mathrm{CN}(\mathrm{B})$

Gradient $(\mathrm{A}) \rightarrow(\mathrm{B})$ for $30 \mathrm{~min}$, following to $(\mathrm{B})$ for $20 \mathrm{~min}$.

Flow rate: $1.0 \mathrm{ml} / \mathrm{min}$, detection: $\mathrm{UV}-230 \mathrm{~nm}$, injection: $20 \mu \mathrm{l}$

Table 1. Extraction of Sucrose Mono- and Di-Fatty Acid Esters from Various Kinds of Foods by Several Solvents $(n=3) \quad(\%)$

\begin{tabular}{lllccccc}
\hline \hline & $\mathrm{SuE}$ & $\mathrm{THF}$ & iso-BuOH & $\mathrm{MeOH}$ & $\mathrm{CHCl}_{3}$ & $\mathrm{CHCl}_{3}: \mathrm{MeOH}(1: 1)$ & $\left(\mathrm{CH}_{2} \mathrm{Cl}\right)_{2}$ \\
\hline \multirow{2}{*}{ Margarine } & $\mathrm{Mo}$ & 99.7 & 88.8 & 87.9 & 41.9 & 68.2 & 15.9 \\
\cline { 2 - 8 } & $\mathrm{Di}$ & 99.4 & 91.2 & 84.6 & 77.7 & 91.3 & 55.1 \\
\hline \multirow{2}{*}{ Ice cream } & $\mathrm{Mo}$ & 85.5 & 77.7 & 49.8 & 0.0 & 44.2 & 0.0 \\
\cline { 2 - 8 } & $\mathrm{Di}$ & 94.3 & 98.1 & 62.8 & 40.9 & 46.6 & 0.0 \\
\hline \multirow{2}{*}{ Curry roux } & $\mathrm{Mo}$ & 96.5 & 96.3 & 76.2 & 80.0 & 72.1 & 5.5 \\
\cline { 2 - 8 } & $\mathrm{Di}$ & 98.9 & 94.9 & 57.0 & 90.0 & 62.5 & 70.5 \\
\hline \multirow{2}{*}{ Cookie } & $\mathrm{Mo}$ & 83.5 & 76.0 & 64.5 & 29.5 & 72.2 & 11.4 \\
\cline { 2 - 7 } & $\mathrm{Di}$ & 94.6 & 103.3 & 70.2 & 100.1 & 94.6 & 36.2
\end{tabular}

Addition level of a mixture of the mono- and diesters was $0.1 \%$.

開するとトリグリセリド，ステロールエステル類などの 非極生物質が溶出された。次いでアセトンークロロホル ム混液 (30:70) $100 \mathrm{ml}$ で展開するとプロピレングリコ 一ル脂肪酸エステル，グリセリンモノ， シ脂肪酸エステ ル, トコフェロール類, ステロール類, ソルビタン脂肪 酸ジェステルが溶出された. 最後にメタノールークロロ ホルム混液 $(50: 50) \quad 100 \mathrm{ml}$ で展開すると SuE とソル
ビタン脂肪酸モノエステルとが溶出される.しかし, HPLC 上ではソルビタン脂肪酸モノエステルは SuEよ り速く溶出するため妨害にはならなかった。 また， ショ 糖, グリセリン及びプロピレングリコールなどは HPLC において溶媒（テトラヒドロフラン，アセトニトリル） ピークと重複して溶出するので定量精度に影響を及ぼさ なかった。 


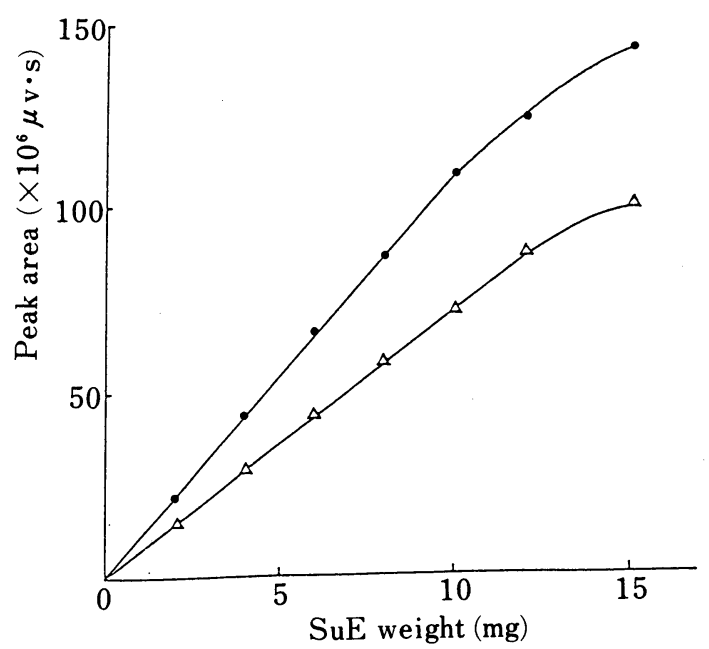

Fig. 4. Calibration curves of DNBC-derivatives of sucrose mono- and di-fatty acid esters 3,5-DNBC: $100 \mathrm{mg} ; 10 \%$ TEA: $1 \mathrm{ml}$ : monoesters; $\triangle \longrightarrow \triangle$ : diesters

Table 2. Recoveries of Sucrose Mono- and DiFatty Acid Esters Added to Several Kinds of Foods

$$
(n=3) \quad(\%)
$$

\begin{tabular}{llcc}
\hline \hline Foods & $\mathrm{SuE}$ & $\bar{X}$ & $\mathrm{CV}$ \\
\hline \multirow{2}{*}{ Margarine } & $\mathrm{Mo}$ & 94.7 & 0.62 \\
\cline { 2 - 4 } & $\mathrm{Di}$ & 86.5 & 0.78 \\
\hline \multirow{3}{*}{ Ice cream } & $\mathrm{Mo}$ & 81.2 & 0.33 \\
\cline { 2 - 4 } & $\mathrm{Di}$ & 82.0 & 0.96 \\
\hline \multirow{2}{*}{ Cookie } & $\mathrm{Mo}$ & 81.0 & 1.12 \\
\cline { 2 - 4 } & $\mathrm{Di}$ & 92.1 & 0.72 \\
\hline \multirow{2}{*}{ Curry roux } & $\mathrm{Mo}$ & 91.7 & 1.47 \\
\cline { 2 - 4 } & $\mathrm{Di}$ & 86.0 & 2.45 \\
\hline \multirow{2}{*}{ Coffee whitener } & $\mathrm{Mo}$ & 81.4 & 3.78 \\
\cline { 2 - 4 } & $\mathrm{Di}$ & 77.7 & 3.18 \\
\hline Addition
\end{tabular}

Addition level of a mixture of the mono- and diesters was $0.1 \%$.

\section{5. 検 量 線}

実験方法 6. の SuE 定量用標準品の調製に従って調製 した場合，モノエステルの高純度品を得るのは比較的容 易である. しかし, ジェステル画分は, トリ, テトラエ ステルなどが混入しやすいので 4 画分に細分した. Fig. 4 はモノ及びジェステルを用いて作成した検量線であ る. モノェステルでは $10 \mathrm{mg}$ まで, ジェステルでは 12 mg まで原点を通る良好な直線性が得られた。

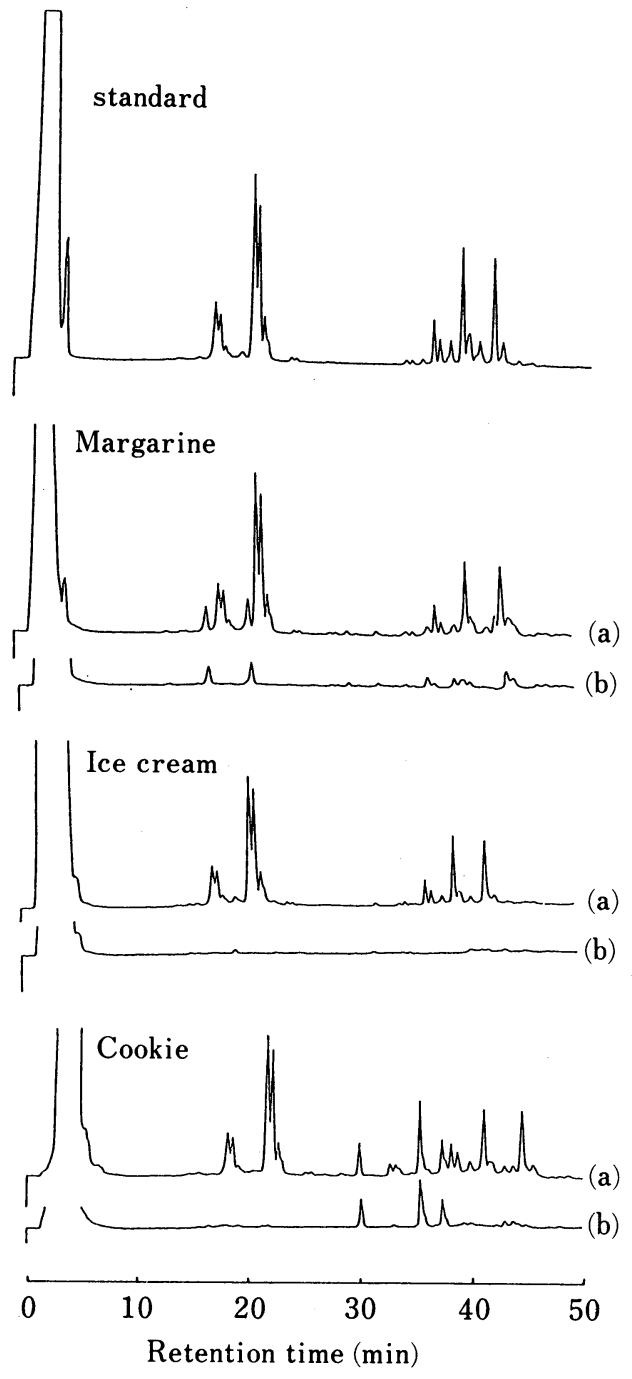

Fig. 5. Liquid chromatograms obtained from several kinds of foods added a mixture of sucrose mono- and di-fatty acid esters or not by the proposed procedure

(a): added the mixture; (b): no addition HPLC condition: column, Inertsil C8 (4.6 $\mathrm{mm}$ i.d. $\times 250 \mathrm{~mm}$ ); mobile phase, $15 \%$ $\mathrm{H}_{2} \mathrm{O}$ in $\mathrm{CH}_{3} \mathrm{CN}(\mathrm{A})$ and $100 \% \mathrm{CH}_{3} \mathrm{CN}(\mathrm{B})$ Gradient $(\mathrm{A}) \rightarrow(\mathrm{B})$ for $30 \mathrm{~min}$, following to (B) for $20 \mathrm{~min}$.

Flow rate: $1.0 \mathrm{ml} / \mathrm{min}$; detection: $\mathrm{UV}$ $230 \mathrm{~nm}$; injection: $20 \mu \mathrm{l}$

\section{6. 添加回収実験}

市販のマーガリン, アイスクリーム，カレールー、コ 一ヒーホワイトナーにモノ及びジェステルの混合物を $0.1 \%$ 添加し，また，クッキーは自製したものを用い添 
Table 3. Contents of Sucrose Mono- and Di-Fatty Acid Esters in Commercial Foods

\begin{tabular}{|c|c|c|c|c|c|c|c|}
\hline & & \multicolumn{4}{|c|}{ Mono } & \multirow{2}{*}{$\mathrm{Di}$} & \multirow{2}{*}{ Mono + Di } \\
\hline & & $\mathrm{C}_{14}$ & $\mathrm{C}_{16}$ & $\mathrm{C}_{18}$ & Total & & \\
\hline \multirow[t]{2}{*}{ Margarine } & (A) & 0.011 & 0.523 & 0.103 & 0.637 & 0.067 & 0.704 \\
\hline & (B) & nd & nd & nd & 0 & nd & 0 \\
\hline \multicolumn{2}{|l|}{ Cookie } & nd & 0.021 & 0.048 & 0.069 & 0.058 & 0.127 \\
\hline \multirow[t]{2}{*}{ Curry roux } & (A) & nd & 0.007 & 0.017 & 0.024 & 0.022 & 0.470 \\
\hline & (B) & nd & nd & nd & 0 & nd & 0 \\
\hline \multirow[t]{3}{*}{ Tablet* } & (A) & nd & 0.034 & 0.101 & 0.135 & 0.335 & 0.650 \\
\hline & (B) & nd & 0.010 & 0.030 & 0.040 & 0.066 & 0.106 \\
\hline & (C) & nd & 0.003 & 0.006 & 0.009 & 0.064 & 0.073 \\
\hline \multicolumn{2}{|c|}{ Whipped cream } & nd & 0.019 & 0.043 & 0.062 & 0.060 & 0.122 \\
\hline
\end{tabular}

(A), (B), (C): different sample * Tablet ty pe confectionery fortified with calcium and dietary fiber.

Table 4. Comparison of Fatty Acid Composition of Mono Acyl Esters of Sucrose in Commercial Foods by the Proposed and the GLC Methods

\begin{tabular}{lllll}
\hline \multirow{2}{*}{ Margarine } & & \multicolumn{3}{c}{ Fatty acid (\%) } \\
\cline { 2 - 5 } & & $\mathrm{C}_{14}$ & $\mathrm{C}_{16}$ & $\mathrm{C}_{18}$ \\
\hline \multirow{2}{*}{ Cookie } & HPLC & 1.7 & 82.2 & 16.1 \\
\cline { 2 - 5 } & GLC & 2.8 & 79.6 & 17.6 \\
\hline \multirow{3}{*}{ Curry roux } & HPLC & & 30.4 & 69.6 \\
\hline \multirow{2}{*}{ Tablet (A) } & HPC & 31.4 & 68.6 \\
\cline { 2 - 5 } & GLC & & 27.5 & 72.5 \\
\hline \multirow{2}{*}{ Tablet (B) } & HPLC & 25.0 & 75.0 \\
\hline & GLC & 27.9 & 72.1 \\
\hline \multirow{2}{*}{ Whipped cream } & HPLC & 24.7 & 75.3 \\
\cline { 2 - 5 } & GLC & 25.6 & 74.4 \\
\hline & HPLC & 30.5 & 69.5 \\
\hline
\end{tabular}

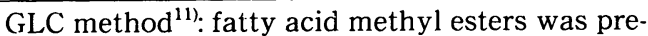
pared from the isolated sucrose mono-fatty acid esters.

加回収率を求めた (Table 2). いずれの食品においても回 収率はモノエステルで，80\%以上，また，ジェステルで は $75 \%$ 以上であった。これらの変動係数は $3.78 \%$ 以内 であり，定量法として十分満足できる精度であると考え る.

Fig. 5 はマーガリン, アイスクリーム及びクッキーの
添加回収実験における SuE のクロマトグラムである. マーガリン及びアイスクリームでは SuE のピークのみ であるがクッキー及びカレールーではジェステルの前に 数本のピークが現れた. しかし，これらは明らかに SuE とは保持時間が異なるので定量の妨害にはならなかっ た.

\section{7. 市販品への応用}

市販食品の分析結果を Table 3 に示した. モノエステ ルはアシル基別に定量した合計值で，ジェステルはそれ に相当する全ピーク面積を加算して求めた.

SuE が検出された食品を再度 5 . 試験溶液の調製の 5. 2 シリカゲルカラムによる精製に従って SuE を分取し, その脂肪酸組成をけん化後常法 ${ }^{11}$ に従って GLC で分析 し, それと本法で得たモノエステル部分の脂肪酸組成と 比較した. Table 4 はその結果である. 本法と GLC で分 析した組成はよく一致した。このことから, SuEモノエ ステルの構成脂肪酸を HPLC で，直接知ることができ ることが明らかになった。

\section{まとめ}

HPLC による各種食品中の SuE の定量法について検 討した. その結果, $\mathrm{SuE}$ をテトラヒドロフランで抽出 し，シリカゲルカラムで精製後，DNBCでエステル化す る定量法を確立することができた。本法はモノ及びジェ ステルを濃度勾配法で溶出することにより，これらの分 別定量, 更にモノェステルについては，構成する脂肪酸 の種類別にも定量することができた．最少検出量はモノ 及びジェステルの各々 $0.001 \%$ である．この検出量は GPC カラムを用い， RI 検出器によって測定する方法の 約 1/100 以下である.

本研究に当たり，貴重な試料を御提供頂いた第一工業 製薬(株)，また適切な御助言を頂いた(財) 日本食品油脂 検查協会理事兼松 弘博士に深謝致します。なお，本研 究の要旨は, 日本食品衛生学会第 56 回学術講演会 
（1988 年 11 月，静岡）において発表した.

文献

1）衛生技術会編：“食用乳化剂と乳化技術” p. 112～137 (1979).

2）山田敏伸, 河瀬伸行, 萩本賢治：油化学. 29, 543 553 (1980).

3）石館守三, 谷村顕雄 監修: “食品添加物公定書解説書” D-522 (1987) 廣川書店.

4) 四方田千佳子, 豊田正武, 伊藤誉志男: 食衛誌. 27,235 239 (1986)

5）厚生省㻴境衛生局食品化学課編：“食品中の食品添加物の
分析法” p. 165 169 (1982) 講談社.

6) Jaspers, M. E. A. P., Leeuwen, F. F. van., Nieuwenhuis, H. J. W., Vianen, G. M.: J. Am. Oil Chem. Soc. 64, 1020 1025 (1987).

7）村上千秋, 丸山武紀, 新谷 勛：食衛誌. 29, 235 239 (1988).

8）石束哲夫, 中村槇吾，鉿木愛子：栄養と食糧. 27，289 293 (1974).

9）大竹俊樹，玉手英四朗：工化誌. 67, 809 812 (1964).

10）大竹俊樹：精糖技術研究会誌. 12, 25 34 (1963).

11）日本油学協会編：基準油脂分析試験法 2.4.21.2 73. 